\title{
On the design of high-rise buildings with a specified level of reliability
}

\author{
Andrey Dolganov ${ }^{1}$, and Pavel Kagan ${ }^{2, *}$ \\ ${ }^{1}$ Ltd "Sev. R. Development", Syromyatnicheskaya Nizh., 10 p. 2, Moscow, 105120, Russia \\ ${ }^{2}$ Moscow State University of Civil Engineering, Yaroslavskoe shosse, 26, Moscow, 129337, Russia
}

\begin{abstract}
High-rise buildings have a specificity, which significantly distinguishes them from traditional buildings of high-rise and multi-storey buildings. Steel structures in high-rise buildings are advisable to be used in earthquake-proof regions, since steel, due to its plasticity, provides damping of the kinetic energy of seismic impacts. These aspects should be taken into account when choosing a structural scheme of a high-rise building and designing load-bearing structures. Currently, modern regulatory documents do not quantify the reliability of structures. Although the problem of assigning an optimal level of reliability has existed for a long time. The article shows the possibility of designing metal structures of high-rise buildings with specified reliability. Currently, modern regulatory documents do not quantify the reliability of high-rise buildings. Although the problem of assigning an optimal level of reliability has existed for a long time. It is proposed to establish the value of reliability $0.99865(3 \sigma)$ for constructions of buildings and structures of a normal level of responsibility in calculations for the first group of limiting states. For increased (construction of high-rise buildings) and reduced levels of responsibility for the provision of loadbearing capacity, it is proposed to assign respectively $0.99997(4 \sigma)$ and $0.97725(2 \sigma)$. The coefficients of the use of the cross section of a metal beam for different levels of security are given.
\end{abstract}

\section{Introduction}

High-rise buildings have a specificity, which significantly distinguishes them from traditional buildings of high-rise and multi-storey buildings. Among the main features of high-rise buildings are:

- Significant values of both static and dynamic loads on load-bearing structures and on bases;

- high, sometimes critical value of horizontal (first of all, wind) loads;

- problems of unevenness, both the magnitude of the loads, and the nature of their application; - careful and correct selection of construction materials, which excludes separate operation of structural elements and ensures homogeneity of physical and mechanical characteristics.

These aspects should be taken into account when choosing a structural scheme of a highrise building and designing load-bearing structures.

\footnotetext{
* Corresponding author: kagan@mgsu.ru
} 
Bearing structures of high-rise buildings in the initial period of development of this type of construction were mainly made of steel. And today in buildings with a height of more than $300 \mathrm{~m}$, including "ultra-high" buildings, steel structures are used for bearing elements. Assembly of factory installation elements on the construction site is carried out with the help of bolted connections, which allows to increase the accuracy of installation by eliminating warpage of steel structures under the influence of high temperatures.

Steel structures are advisable to be used in seismic resistant regions, since steel, due to its plasticity, provides damping of the kinetic energy of seismic impacts. At the same time, steel structures require mandatory reliable protection against fire, since at $300^{\circ} \mathrm{C}$ the strength of steel is sharply reduced [1-13].

\section{Materials and Methods}

Currently, modern regulatory documents do not quantify the reliability of structures. Although the problem of assigning an optimal level of reliability has existed for a long time. Thus, in 1890, the Russian version of Hütte 's handbook [11] with a developed system of reliability coefficients was published. In 1926, prof. M. Maier published a paper [12] in which he criticizes the calculation of the allowed voltages and proposes to calculate the designs from the account of an unprofitable combination of loads and material resistances. In 1929 N.F. Khotsialov [10] developed the ideas of M. Mayer. He, referring to the stochastic variability of mechanical and geometric parameters of structures, instead of the slogan "Build without destruction, by all means" proposed a new one - "Construction with an expedient number of destructions." Design, according to N.F. Khotsialov, should be conducted taking into account both capital costs and probable "defective deviations" and the amount of losses caused to the state by an accident.

In 1945, in connection with the development of new norms for calculation and design, the Commission for the unification of calculation methods, organized by the Narkomtyazhstroy adopted a conditional scheme of design coefficients proposed by I.I. Gol'denblat, M.G. Kostyukovsky, A.M. Popov. According to this scheme, the overall safety factor depended on the coefficients of homogeneity, overloads and operating conditions of the structure. In the future, the proposed scheme was included in the calculation method for limiting states. It was accepted that the designs must meet the requirements for them with a reasonable degree of risk.

Abroad [1], the formula for the normalization of the probability of failure $Q(t)$ became very popular:

$$
Q(t)=10^{-5} \xi_{S} T / L
$$

where $\xi_{S}$ - coefficient of social significance (Table 1); $T$ - estimated service life in years; $L$ is the average number of people inside the building or in its immediate vicinity during the period for which the risk is assessed.

Table 1. Coefficient of social significance $\xi_{S}$

\begin{tabular}{|l|l|}
\hline Type of construction & $\xi_{s}$ \\
\hline Places of meeting of people, dams & 0.005 \\
\hline Residential, office, commercial and industrial buildings & 0.05 \\
\hline Bridges & 0.5 \\
\hline Towers, masts, structures on the sea shelf & 5 \\
\hline
\end{tabular}

For buildings of a normal level of responsibility, the required reliability, $R(t)$, according to (1) will be: 


$$
\mathrm{R}(\mathrm{t})=1-\mathrm{Q}(\mathrm{t})=1-10^{-5} \times 0.5 \times 50 / 50=0.999995 \text { or } 0.9^{5} 5 .
$$

Professor Ryush (table 2) proposes to normalize the reliability of $P(t)$ constructions in the probability of their failure $Q(t)$, where $Q(t)=1-P(t)$.

Table 2. Rationing of reliability of reinforced concrete structures

\begin{tabular}{|l|c|}
\hline \multicolumn{1}{|c|}{ Type and characteristics of failure } & $\boldsymbol{Q ( t )}$ \\
\hline $\begin{array}{l}\text { Failure without preliminary signals (brittle failure, loss of stability, } \\
\text { etc.) }\end{array}$ & $10^{-7} \ldots 10^{-5}$ \\
\hline Loss of load capacity with a preliminary signal & $10^{-4}$ \\
\hline $\begin{array}{l}\text { Inability to normal operation without loss of load capacity (similar } \\
\text { to the 2nd group of limit states) }\end{array}$ & $10^{-3} \ldots 10^{-2}$ \\
\hline
\end{tabular}

In the Russian Federation, the reliability of the mechanical characteristics of materials for reinforced concrete and metal structures is regulated by GOST 5781-82 *, GOST R 525442006 for rod reinforcement, GOST 18105-2010 for concrete, and also by the building rules of SP 63.13330-2012 "Concrete and reinforced concrete structures" and SP 16.13330-2016 "Steel structures". The reliability of loads is regulated by SP 20.13330.2016 "Loads and impacts".

According to these documents, the reliability (security) of the material's standard resistances is assumed to be $0.95(1.64 \sigma)$, and the availability of design resistances is approaching $0.99865(3 \sigma)$ : the standard resistances are divided by the reliability coefficients for materials that are greater than 1. Constant and long-term normative loads are defined as mathematical expectations (mean values) of physical characteristics of materials. Normative time loads are the mathematical expectations of extreme technological or natural processes. For calculations on the first group of limiting states, the standard loads are multiplied by the reliability factor, which is usually greater than 1.

Thus, in the calculations for the first group of limiting states of the resistance of materials, they have a security of about $0.99865(3 \sigma)$, and the load security varies from 0.6 to 1 . In the calculations for the second group, the limiting states of the resistance of materials have a 0.95 $(1.645 \sigma)$, and the load is approximately 0.5 .

Therefore, the value of reliability $0.99865(3 \sigma)$ in calculations for load-bearing capacity and should be assigned to structures of buildings and structures of a normal level of responsibility. For increased and reduced levels of responsibility [3], the load-bearing capacity should be assigned with respectively $0.99997(4 \sigma)$ and $0.97725(2 \sigma)$.

\section{Results}

To prove the rigidity of structures, consider a simple example. In calculations for the second group of limiting states, for example, the calculated deflection $f$ we compare with the permissible [f]. That is, we achieve the fulfillment of the condition:

$$
f \leq[f]
$$

In formula (3), the calculated parameters are represented by their mathematical expectations. It follows that the results obtained by formula (3) have a security close to 0.5 .

Table 3 summarizes the formulated proposals for designating the level of reliability of building structures, depending on the group of limit states (PS). 
Table 3. Proposals for designation of the level of reliability of building structures

\begin{tabular}{|c|c|c|}
\hline $\begin{array}{c}\text { Level of responsibility of } \\
\text { structures }\end{array}$ & $\begin{array}{c}\text { Provision for the group I of } \\
\text { limit states }\end{array}$ & $\begin{array}{c}\text { Provision for group II of } \\
\text { limit states }\end{array}$ \\
\hline Increased & $0.99997(4 \sigma)$ & $0.95(1.64 \sigma)$ \\
\hline Normal & $0.99865(3 \sigma)$ & $0.50(0 \times \sigma)$ \\
\hline Reduced & $0.97725(2 \sigma)$ & $\begin{array}{c}\text { Not regulated } \\
\text { (if condition (3) is fulfilled } \\
\text { for constant and long-term } \\
\text { loads) }\end{array}$ \\
\hline
\end{tabular}

Let us consider an example of designing a metal beam with a specified reliability of $0.97725(2 \sigma)$ in terms of bearing capacity for constructing a reduced level of responsibility [3]. The span of the beam is $10 \mathrm{~m}$. The standard and design loads are given in Table 4.

Table 4. Normative and design loads (example)

\begin{tabular}{|l|c|c|c|}
\hline \multicolumn{1}{|c|}{ Name of the load } & Normative, $\mathbf{k N / \mathbf { m } ^ { 2 }}$ & $\begin{array}{c}\text { Coefficient } \\
\text { reliability, } \boldsymbol{\gamma}_{\mathbf{f}}\end{array}$ & $\begin{array}{c}\text { Estimated, } \\
\mathbf{k N} / \mathbf{m}^{\mathbf{2}}\end{array}$ \\
\hline Net weight of the beam & 0.14 & 1.05 & 0.15 \\
\hline Mechanisms of airing & 0.02 & 1.10 & 0.02 \\
\hline Coating flooring & 0.65 & 1.10 & 0.72 \\
\hline Snow & 1.00 & 1.40 & 1.40 \\
\hline Connections horizontal & 0.06 & 1.05 & 0.06 \\
\hline Total: & 1.87 & - & 2.34 \\
\hline
\end{tabular}

For the loads given in Table 4, we determine the required moment of resistance of the section of the beam, $\mathrm{m}^{3}$, from the condition for the strength of normal sections:

$$
\mathrm{W}=\mathrm{M} /\left(\mathrm{R}_{\mathrm{y}} \gamma_{\mathrm{c}}\right)=2.34 \times 2 \times 10^{2} / 8 /(245000 \times 0.9)=0.000265 .
$$

According to the assortment we take the I-beam 26B1, w $=0.000312 \mathrm{~m}^{3} ; \mathrm{J}=0.00004024$ $\mathrm{m}^{4}$. The coefficient of section usage will be:

$$
\mathrm{k}=\mathrm{qL}^{2} /\left(8 \mathrm{R}_{\mathrm{y}} \gamma_{\mathrm{cW}}\right)=2.34 \times 2 \times 10^{2} /(8 \times 245000 \times 0.9 \times 0.000312)=0.852 .
$$

Let us check the rigidity of the beam. The allowable deflection is:

$[\mathrm{f}]=\mathrm{L} / 250=10000 / 250=40 \mathrm{~mm}$.

The calculated deflection is:

$$
\begin{gathered}
\mathrm{f}=5 / 384 \times \mathrm{qL}^{4} /(\mathrm{EJ})=5 / 384 \times 1.87 \times 2 \times 10^{4} /(200000000 \times 0.00004024)= \\
0.048 \mathrm{~m} .
\end{gathered}
$$

As can be seen from (5), the calculated deflection exceeds the allowable deflection by 1.2 times.

We estimate the reliability of the beam, taking into account the variability of the random variables. Random resistance is the steel resistance and the total value of the loads.

To calculate the reliability of the cross sections, we use the linearization method (6) (10). This method assumes a formula dependence of the function of random arguments, and this dependence must be differentiable. 


$$
\begin{gathered}
m_{Y}=\varphi\left(m_{X_{1}}, m_{X_{2}}, \ldots, m_{X_{n}}\right) \\
D_{Y}=\sum_{i=1}^{n}\left(\frac{\partial \varphi}{\partial x_{i}}\right)_{m}^{2} \cdot D_{X_{i}}+2 \sum_{i<j}^{n}\left(\frac{\partial \varphi}{\partial x_{i}}\right)_{m}\left(\frac{\partial \varphi}{\partial x_{j}}\right)_{m} K_{i j}
\end{gathered}
$$

or through the mean square deviations:

$$
\begin{gathered}
\sigma_{Y}^{2}=\sum_{i=1}^{n}\left(\frac{\partial \varphi}{\partial x_{i}}\right)_{m}^{2} \sigma_{x_{i}}^{2}+2 \sum_{i<j}^{n}\left(\frac{\partial \varphi}{\partial x_{i}}\right)_{m}\left(\frac{\partial \varphi}{\partial x_{j}}\right)_{m} r_{i j} \sigma_{x_{i}} \sigma_{x j} \\
r_{i j}=K_{i j} /\left(\sigma_{i} \cdot \sigma_{j}\right) .
\end{gathered}
$$

where $r_{i j}, \sigma_{x_{i}}, \sigma_{x_{j}}$-respectively, the correlation coefficient and the mean square deviations of the random variables $X_{i}, X_{j} ; K_{i j}$ - is the correlation moment of the random variables $X_{i}, X_{j}$ :

$$
K_{i j}=M\left[\left(X_{i}-m_{X i}\right)\left(X_{j}-m_{X j}\right)\right] .
$$

The average values, $q_{m}$, and the load variation coefficient, $v_{q}$, are determined from Table 3 . The average value of steel resistance, $R_{y m}$, is determined with the coefficient of variation, $V_{s}$, equal to 0.04 .

In this way,

$\mathrm{q}_{\mathrm{m}}=1.87 \mathrm{kN} / \mathrm{m}^{2}$;

$\mathrm{V}_{\mathrm{q}}=[(2.34-1.87) / 1.64] / 1.87=0.156$;

$\mathrm{R}_{\mathrm{ym}}=250000 /(1-1.64 \times 0.04)=267550 \mathrm{kN} / \mathrm{m}^{2}$.

The average square deviations of the resistance of steel and loads are respectively equal, $\mathrm{kN} / \mathrm{m}^{2}: \sigma_{\mathrm{s}}=267550 \times 0.04=10702 ; \sigma_{\mathrm{q}}=1.87 \times 0.156=0.291$.

We take the partial derivatives in (4) with respect to $R_{y}$ and $q$, and substitute $R_{y}$ and $q$ $R_{y m}$ and $q_{m}$. in the expressions obtained. When calculating by formulas $(11)-(12) \gamma_{c}$ is equal to 1 ; the load distributed per $1 \mathrm{~m}^{2}$ is reduced to the running load, multiplying by a step the beams, equal to $2 \mathrm{~m}$. We obtain

$$
\begin{gathered}
\partial \mathrm{Y}_{\mathrm{k}} / \partial \mathrm{R}_{\mathrm{y}}=-\mathrm{q}_{\mathrm{m}} 1^{2} /\left(8 \mathrm{R}_{\mathrm{ym}}^{2} \gamma_{\mathrm{c}} \mathrm{w}\right)=-1.87 \times 10^{2} /\left(8 \times 267550^{2} \times 0.000312\right)= \\
2.09 \times 10^{-6} \\
\partial \mathrm{Y}_{\mathrm{k}} / \partial \mathrm{q}_{\mathrm{m}}=1^{2} /\left(8 \mathrm{R}_{\mathrm{ym}} \gamma_{\mathrm{c}} \mathrm{w}\right)=10^{2} /(8 \times 267550 \times 0.000312)=0.299 .
\end{gathered}
$$

Using formula (8), taking into account (4), we determine the standard deviation of the coefficient of cross-section use, MPa:

$$
\sigma_{\mathrm{k}}=\left[\left(2.09 \times 10^{-6}\right)^{2} \times 10702^{2}+0.299^{2} \times 0.291^{2}\right]^{1 / 2}=0.09 .
$$

We define the reliability index $\mathrm{t}$ for $\mathrm{k}=0.852$ :

$$
\mathrm{t}=(1-\mathrm{k}) / \sigma_{\mathrm{k}}=(1-0.852) / 0.09=1.648 .
$$


For the normal distribution law, the bearing capacity of the beam under consideration $P$ (t) is 0.95 , which is somewhat lower than the required value of 0.97725 according to Table 3.

We define the derivative with respect to $\mathrm{q}$ of the deflection function $(5), \mathrm{m}^{3} / \mathrm{kH}$ :

$$
\begin{gathered}
\partial \mathrm{Y}_{\mathrm{k}} / \partial \mathrm{q}_{\mathrm{m}}=5 / 384 \times \mathrm{B} \times \mathrm{L}^{4} /(\mathrm{EJ})=5 / 384 \times 2 \times 10^{4} /(200000000 \times 0.00004024)= \\
0.03 .
\end{gathered}
$$

By (8), we determine the standard deviation of the deflection function, $\mathrm{m}$ :

$$
\sigma_{\mathrm{f}}=\left(0.03^{2} \times 0.291^{2}\right)^{1 / 2}=0.0094 .
$$

We define the reliability index $\mathrm{t}$ for the actual deflection $\mathrm{f}=0.048$ :

$$
\mathrm{t}=([\mathrm{f}]-\mathrm{f}) / \sigma_{\mathrm{f}}=(0.040-0.048) / 0.0094=-0.883 \text {. }
$$

\section{Discussion}

For the normal distribution law, the security of the deflections (rigidity of the beam under consideration) $\mathrm{P}(\mathrm{t})$ is 0.1887 . The probability of exceeding the deflections from the load limits calculated for the second group is 0.8113 .

Define the design parameters for which the load carrying capacity and rigidity of the structure would correspond to the specified reliability values. The required security according to the carrying capacity according to Table 3 is $0.97725(2 \sigma)$, and for normal operation it is not regulated.

The coefficient of cross-section use for the security of $0.97725(2 \sigma)$ is:

$$
[\mathrm{k}]=1-2 \sigma_{\mathrm{k}}=1-2 \times 0.09=0.82 .
$$

It is sufficient that the cross-section of the middle part of the beam with a length of $3 \mathrm{~m}$ is symmetrically reinforced with plates $0.7 \mathrm{~mm}$ thick, so that the coefficient of cross-section usage becomes 0.82 .

For technological reasons we weld plates with a thickness of $3 \mathrm{~mm}$. Reliability by the criterion of bearing capacity has become $0.999232(3.168 \sigma)$. For stiffness -0.264653 .

Thus, section $26 B 1$ reinforced with two plates $3 \mathrm{~mm}$ thick with a length of $3 \mathrm{~m}$, installed in the middle of the beam, meets the requirements of reliability and safety for building a reduced level of responsibility. The coefficient of use of the cross section for the case under consideration became 0.754 .

\section{References}

1. G. Augusti, A. Baratta, F. Kashiati, Veroyatnostnye metody v stroitel'nom proektirovanii (Stroyizdat, Moscow, 1988)

2. A. Gemmerling On the Reliability of Mass Structures, Stroitel'naya mekhanika i raschet sooruzheniy, 5, 69-73 (1974)

3. GOST 27751-2014. Nadezhnost' stroitel'nykh konstruktsiy i osnovaniy (Standartinform, Moscow, 2015)

4. V. Telichenko, E. Korol, P. Kagan, S. Komissarov, S. Arutyunov, Constructive solutions for high-rise buildings, Vysotnyye zdaniya: zhurnal vysotnykh tekhnologiy, 4, 102-109 (2008) 
5. A. Dolganov, Reliability of core reinforced concrete structures (JSC "MAOBTI", Magadan, 2001)

6. A. Dolganov, Optimization of reinforced concrete structures with regard to reliability criteria and minimum cost (Izdatel'stvo Severnogo mezhdunarodnogo universiteta, Magadan, 2002)

7. A. Dolganov, Evaluation of the reliability of rafters F-1 warehouse terminal "Belaya Dacha Market", Sbornik nauchnykh trudov MGSU, 75-77 (2002)

8. A. Rzhanitsyn, The economic principle of calculation for safety, Stroitel'naya mekhanika i raschet sooruzheniy, 3, 3-5 (1973)

9. Rusian State Standard SP 20.13330.2016

10. N. Khotsialov, Stocks of strength, Stroitel'naya promyshlennost, 10, 840 (1929)

11. "Hütte". A reference book for engineers, architects, mechanics and students. The ninth edition. (T-vo skoropechati A.A. Levensona, Moscow, 1916).

12. M. Maier, Die Sicherheit der Bauwerke und ihre Berechnung nach Grenzkräften anstatt nach zulässigen Spannungen (Springer, Berlin, 1926)

13. A. Dolganov, Estimation of the Reliability of the Monolithic Multistory Buildings, Promyshlennoe i grazhdanskoe stroitel'stvo, 8, 50-51 (2010) 